\title{
Translating academic careers into industry healthcare professions
}

\author{
Though academic institutions have contributed enormously to the remarkable growth in the healthcare industry, \\ a key limiting resource for this continued growth is the creation of career opportunities for doctoral graduates.
}

T he strong biotechnology industry in the United States began with the founding of Genentech in 1976 and the subsequent creation of innovation hubs in the San Francisco Bay Area and Cambridge, Massachusetts. In Europe, growth has been slower due to a lack of capital to finance promising startups. In the most prominent example, Biogen was founded in Switzerland but moved early on to the United States, where funding conditions were better.

Innovation hubs with an abundance of capital from venture investors, business angels and government incentives attract not only the most innovative healthcare companies, but also talented individuals contributing brain power to innovation creation. The industry needs two components to survive and grow in the future: capital and talent. While funding and dealmaking continues to break records ${ }^{1-3}$, leading to unprecedented new drug approvals by the $\mathrm{FDA}^{4}$ and fast product development in response to virus outbreaks like Ebola or SARS-CoV-2, talent is a chronically scarce resource ${ }^{5,6}$. Here, we discuss the current state of graduate and postgraduate students in healthcare programs and the ways to translate an academic career into a healthcare industry profession. We summarize various programs in the United States and Europe and how governments, universities, pharmaceutical companies and venture capital investors are working toward creating innovation hotspots to attract and develop the best talent. Finally, we describe possible approaches for shifting one's career from academia to industry and provide information on various programs and events helpful to such a journey.

Companies in the healthcare sector, including pharma, biotech, medtech and e-health companies, require highly trained and specialized talent and spend significant amounts of time and capital on human resources to find and recruit new team members. Students in biomedical graduate programs more often than not pursue an academic research career leading to a $\mathrm{PhD}$

\section{Box 1 | Exploring career options}

The evolution of one's career is often an individual experience filled with questions, yet, as our survey reveals, many of the challenges faced are shared. One common theme of many successful careers is that being proactive helps create options, such as asking experts about their journeys to find their first jobs. In one case, a graduate student one and a half years into her doctoral program started asking her friends on the junior professor track and other colleagues whether she should stay in academia or go look outside for a job. While all academics said she should stay in academia, they also highlighted that if she wanted to leave this was the right time to start preparing. As also seen in our survey (Fig. 1a), the advice given was heavily oriented toward staying in academia. This advice led her to search the graduate school workshop and seminar program, where she saw and applied for a research management training for early-career researchers (for reference and similar programs, see Table 1). In this week-long workshop, she learned about different avenues to exploit biomedical innovations, and also had the chance to exchange thoughts with many people with backgrounds in different STEM fields, business, law and technology transfer. Starting the dialog was the first important step and helped her to take the next one: asking some hard questions that required a great deal of self-reflection and personal assessments of strengths, weaknesses, passions and interests - something that an individual development plan ${ }^{11}$ can help with. Nearly all of the core challenges experienced by her are evident in our survey of approximately 300 biomedical graduates, who perceived many barriers keeping them from following their ideal career path (Fig. 1b). To break down such barriers, we would highly recommend asking experts for their advice about job opportunities and for introductions. This can be highly effective and was a key element of a recent Career Exploration Day organized by the CDI group in Berlin (Table 1). At this event, we recommended follow-up discussions with the experts at the workshop, which in turn led to specific introductions to local CEOs in the Berlin medtech and biotech community and concrete jobs opportunities from employers eager for these talented individuals. In the end, proactive networking is key to launching one's career. degree and postdoctoral studies at academic research institutions. While moving along the academic career path, young scientists realize rather late that principal investigator and faculty positions in academia are scarce (less than $18 \%$ of $\mathrm{PhD}$ graduates will get one) and long-term postdoctoral funding is limited ${ }^{7}$.

To get an idea of the career awareness of biomedical professionals, we conducted a poll of over 300 graduate students (master's degree and $\mathrm{PhD}$ ) and postdocs at various universities in Berlin, Stockholm, Silicon Valley and Tel Aviv (see Box 1, Supplementary Methods and Supplementary Data). We found that while students understood the value of networking and specific expertise to qualify for their current job, their understanding of how to translate a research career to their next job, especially outside academia, seemed to be less clear. Almost all students found their current position through either a job posting or through their network and qualified for employment through specific knowledge and experience. Half of the interviewed academic scholars were actively exploring career options, mostly in academia or industry, and many were uncertain which career path they should choose. In more than half of the cases, a career development office helped to some degree in making 
a

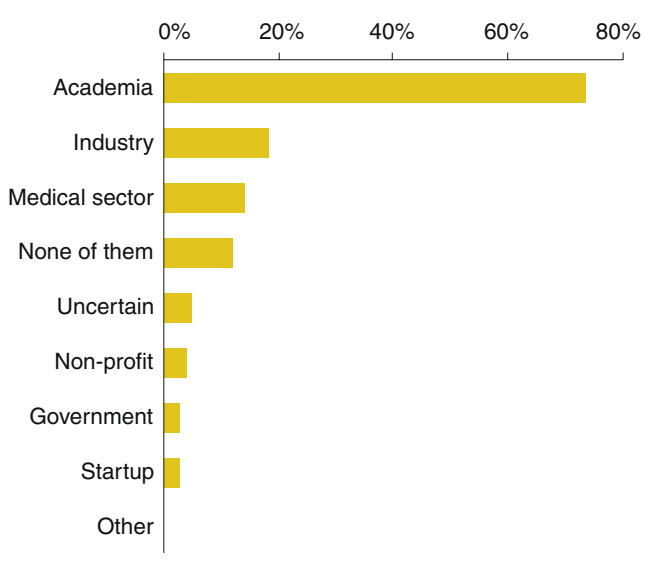

b Career challenges

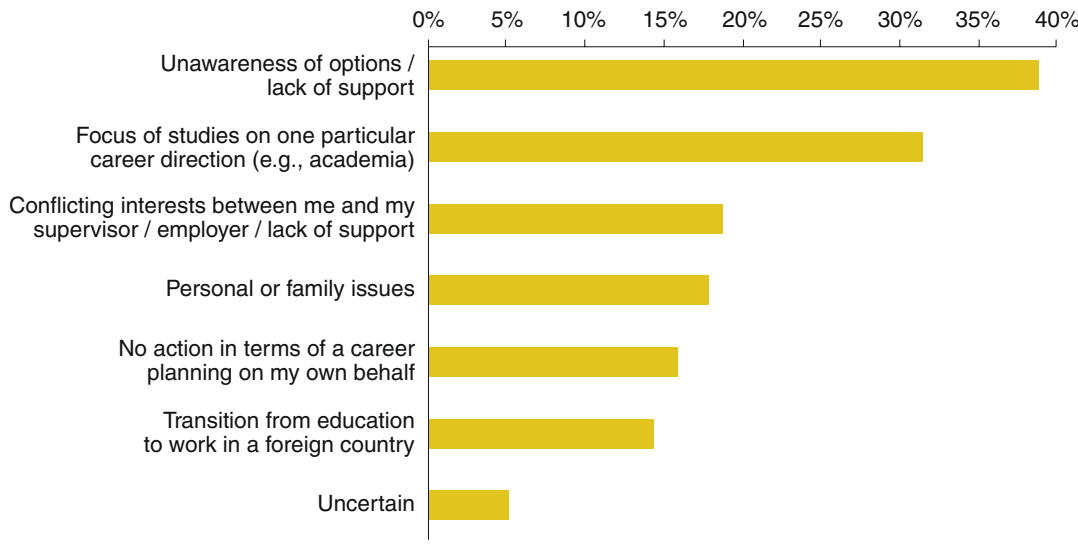

Fig. 1 | Survey results. To gain insight into how biomedical students think about their careers, we conducted a survey of 300 graduate and postgraduate students in the United States and Europe (see Supplementary Methods). a, Students received the most career advice about academic careers. b, A large proportion of students felt a lack of support and awareness of career options blunted their ability to reach their ideal careers.

contacts to alumni networks, while specific offers in form of workshops, training, mentoring or internship facilitation were lacking. Importantly, most students were given advice almost exclusively for academic research careers, and half felt they were unaware of various non-academic career options and were lacking work experience or networking skills to be able to get their dream job. The survey shows that graduates and postgraduates in the life sciences are aware of what is needed to translate academic careers, but seem to lack the knowledge of where to find and establish the skill sets, mentorship and/or networks necessary to facilitate career choice and translation.

\section{Life science career development challenges}

Starting with university career programs, the poll highlights students' needs and desires for additional training in areas outside their core curriculum. While some universities are quite progressive and have developed innovative solutions (Table 1), there is much room for improvement ${ }^{8,9}$. Intriguingly, in a growing number of examples, changes in how universities support career development are being driven by students and postdoctoral fellows themselves. In one such example at Stanford University ${ }^{10}$, pairs of student representatives from each of the major life science graduate programs in developmental biology, neuroscience, cell biology and pharmacology, among others, worked not only to restructure core course requirements, but to increase the fraction of electives that could be taken anywhere across campus, including the schools of education, public policy, engineering and business. They also developed an individual career development plan ${ }^{11}$ to encourage students to think about their talents and core interests, as well as to identify cross-disciplinary mentors both inside and outside academia.

Similarly, graduate students on the shared campus of the Charité Medical School and Humboldt University in Berlin worked together to create the Career Development Initiative (CDI $)^{12}$. The students also established their own individual career development plans and were able to work with their respective programs to design new coursework and permit new training outside of their majors. In addition, they created a lecture series where scientists working in non-academic positions speak about their journey and how they landed their ideal job. The speakers agreed to become mentors and advisors in this program, making personal introductions to companies in the larger Berlin community. Outside speakers represent a valuable mechanism for scholars to learn about skill sets that will be truly useful in the real world. The CDI group also uses design thinking approaches ${ }^{13}$ in workshops to explore career options and prepare for interviews. Moreover, by networking with several local not-for-profit organizations, including Berlin Partners, the students recruit representatives from local biotech and medtech companies to a Young Talent Career Day ${ }^{12}$ where, via a matchmaking algorithm, attendees can be paired with prospective future employees. Many of these features are also seen in programs at top innovation-oriented universities in Europe and the United States (Table 1). Of note, efforts at the Scripps Research Institute have led a graduate level course, Effective Career Planning for $\mathrm{PhDs}$, that advocates for proactive career planning 9 . Finally, there are books that are great resources to help identify one's strengths while matching them to exciting careers ${ }^{14,15}$.

\section{Career opportunities in the healthcare sector}

Companies in the healthcare sector range from large pharmas with tens of thousands of employees to university startups with a handful of team members. Innovations and ideas out of universities are typically financed by government grants, business angels and investors such as venture capital (VC) firms, and the translation from idea to company is in many cases facilitated by several stakeholders: the founding team, the university technology transfer office, intellectual property lawyers, entrepreneurs and VCs themselves.

Recently, the classical VC investment model has shifted more and more toward company creation and early-stage investment in order to bridge the gap between science and capital markets. One of the main tasks of VCs is human resource management. Most VCs spend a significant amount of their time attracting and retaining the best talent for newly financed startups. Since investors search actively for new ideas to invest in and talent to recruit, many have started initiatives to increase talent attraction. The idea behind most programs is to develop the talent pool of tomorrow, allowing the exchange of many different ideas, bringing different technologies together and thereby creating an innovation ecosystem. Some examples of public and private efforts to expand job opportunities that capture young talent in the biomedical areas are highlighted below. 
Table 1 | Some institutions with progressive career development programs for doctoral and postgraduate students

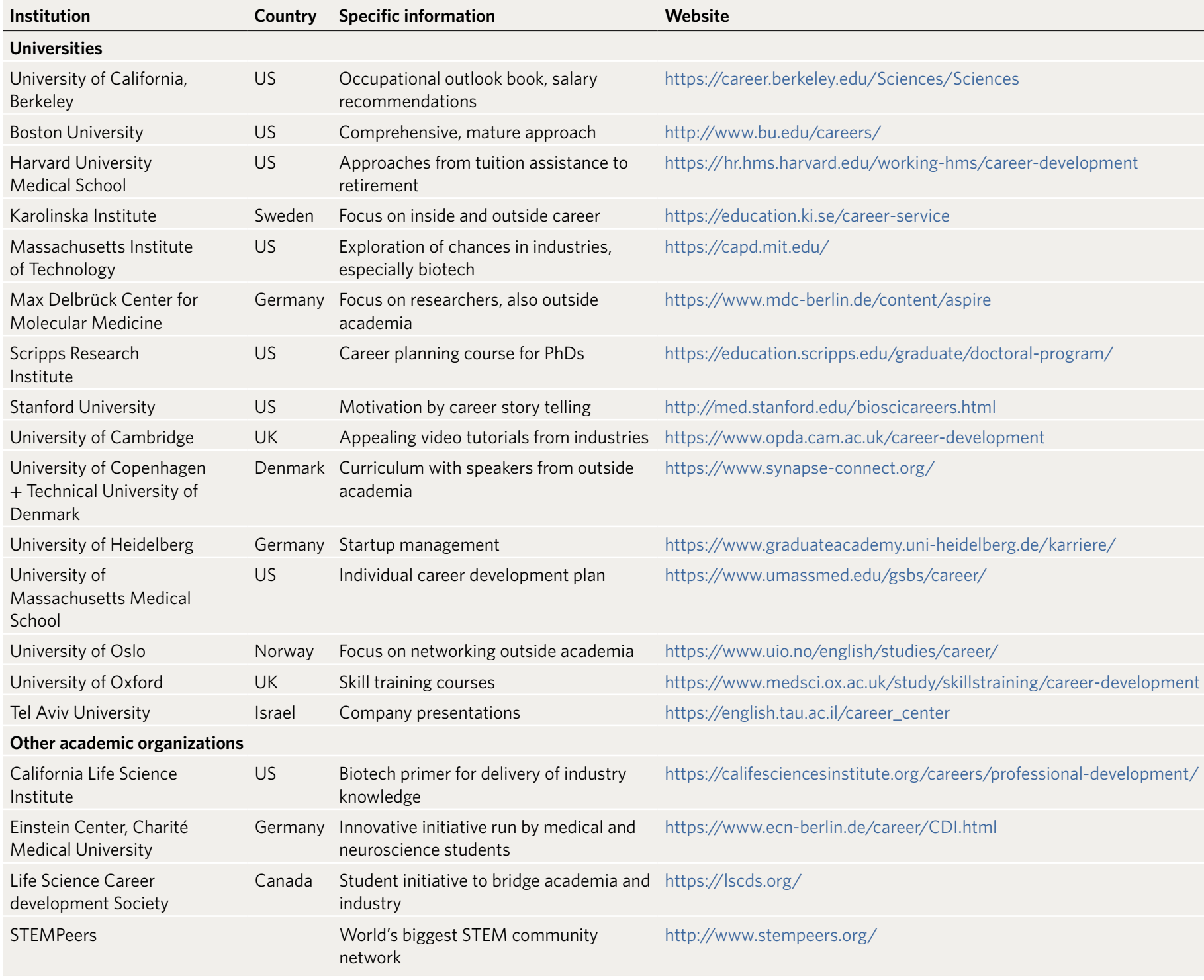

\section{VC internships and fellowships}

Venture capital firms have raised increasingly large funds in recent years, allowing internal investment teams to grow. Today a number of VC funds are large enough to provide in-house internship or fellowship programs on a rolling basis (Table 2). Internships usually last between 6 and 12 months and pay a small salary or are financed by a grant. Programs are directed toward graduate students still enrolled in their $\mathrm{PhD}$ curriculum and looking for early professional experience. Interns usually learn broadly about the healthcare ecosystem, learn how VCs evaluate prospective investments and, most importantly, get exposed to many startup companies. At the same time, VCs are able to see different perspectives and ideas, learn about new trends in academia, enlarge their academic networks and, in the best-case scenario, attract talent for their portfolio companies. Such programs provide an easy way to learn the business aspect of startup companies, become familiar with the drug or device development process and interact with different stakeholders in healthcare. The most valuable lesson from the experience is the understanding that investors work together with a wide range of specialists, giving the intern plenty of opportunities to establish personal relationships and learn as much as they can.

\section{Creating innovation centers and hubs} The foundation of the VIB in the Flanders region of Belgium in 1996 marked the first innovation hub in Europe (Table 2). Since then, the region has developed into one of Europe's most successful biotech hubs, birthing multi-billion-dollar companies such as Ablynx and Argenx. To ensure excellence in science, the VIB pays special attention to the professional development of all co-workers. Human resource development at the VIB includes training, mentoring, coaching and career guidance inside or outside of academia. To do so in an efficient manner, the VIB established its own career center aimed at graduate students. At the VIB and other innovation hubs, graduate students can access a diverse set of resources to attend workshops, receive training in various skill sets and increase their own awareness of different professional skills.

The VIB created an innovation hub similar to the Kendall Square ecosystem in 
Table 2 | Innovation hubs and internships

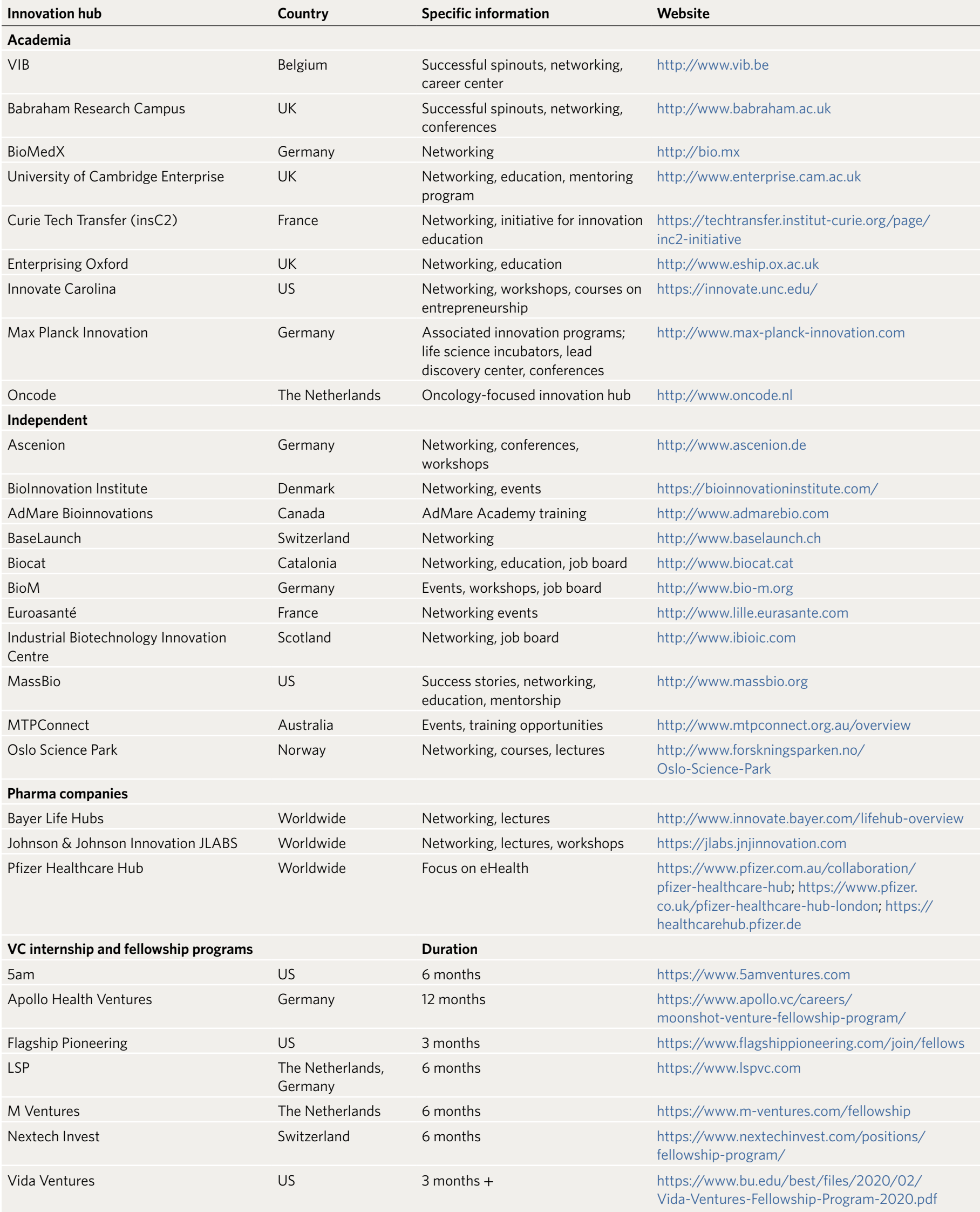


Cambridge, Massachusetts, where scientists, entrepreneurs, and investors from academia, startups, biotech and pharma meet regularly. Such interactions are the first steps to understanding the various opportunities and possibilities for life science graduates. Not every résumé is the same and, more often than not, individuals working in the industry have a diverse skill set that they acquired working in different jobs.

Other innovation hubs have built on the success of the VIB and combine regional excellence with talent development (Table 2). Stakeholders in such hubs vary from region to region depending on regional strategy and the most active business areas. Historically, the Netherlands has a strong VC sector; in fact, the first VC investments were made in Holland, financing expeditions by ship to explore new continents to trade coffee, tea and other resources. Relying on a strong financial sector, a number of biotech companies were created in the Netherlands ${ }^{16}$. However, the academic institutions fueling such innovation are distributed over the country and not well interconnected. Therefore, the Oncode Institute was created to unite scientists under one organization with the mission of translating scientific innovation into new therapies. The shared mission forces researchers to think about their own research from a different angle and provides new possibilities for creative scientists to invent products based on their research topics. Top-quality addition of value by translation of research results requires a highly specialized talent pool. The close proximity of scientists, entrepreneurs, investors and tech transfer specialists, with the shared goal of translating ongoing research, forms the foundation for everyone involved to think beyond their academic career path.

Importantly, large pharmas are also interested in fostering innovation ecosystems, recruiting the best talent and promoting translation of breakthrough science (Table 2). For example, Johnson \& Johnson was one of the first pharmas to create a separate investment arm and innovation department to advance healthcare innovation by collaboration with academia and startups. It created innovation centers for scouting and collaborating and JLABS to incubate early ideas and interact with the eco-environment. JLABS are innovation hotspots in various cities; they engage with the different stakeholders. The interaction encompasses a variety of communication channels, from social media to personal presence at events. JLABS offer a wide range of courses, workshops and talks on various aspects of the life science industry, with topics ranging from discussions on early science to drug approval, the regulatory path and scientific topics. Attendees obtain insights into diverse topics from Johnson \& Johnson employees, entrepreneurs or academic scientists. Together, such initiatives are beginning to bridge the gap between large pharmas, innovative companies and scientists, fostering exchange between people from diverse professions.

\section{Empowering exciting careers}

How can we empower the next generation of young scientists to get the job of their dreams? Scientists in academia may be highly successful, dedicated and innovative, but translating skills developed in an academic setting to an applied profession continues to be a challenge. The process of one's own career translation can be seen as a road with predefined junctions. Like the planning for a road trip, career transitioning needs planning and an idea of where the journey should lead.

The golden rule for all important decisions is to start planning early. For example, when considering a job change or transition from university to industry, the process can usually take a year to a year and a half. Also, some entry-level jobs might only be available to those with prespecified degrees and work experience. This means that, in some cases, it will be easier to enter a large pharma after a master's degree rather than after a postdoctoral fellowship. Thus, an ideal time to start your career transition is to begin shortly after the first year into a master's or $\mathrm{PhD}$ program. At that stage, graduate students usually have a first idea of their academic and lab environment and whether they are passionately focused on an academic path or are already thinking outside the academic box. Take advantage of individual career development plans ${ }^{11,12}$. It is also a good time to tap into local graduate schools, universities and community programs or activities that encourage internships, workshops and other activities outside of the degree curriculum (Table 1) in order to collect as much information as possible on a variety of different professions.

By the second year of graduate education, the collected information can then be used to map the landscape of professions and associated skills required. This allows one to adjust one's curriculum or add another degree qualification in an interdisciplinary study program to meet the requirement of a specific career or profession. To understand one's personal skill set better, one can look at personal preferences and talents cultivated inside and outside academia. In the end, the overlap between required skills and individual talents can inform the selection of professions. While understanding individual strengths and weaknesses is important, interacting with professionals working in jobs of interest is essential to reality-check expectations and further map out details of jobs and personal interests. It also helps to follow the journey in a personal notebook, summarizing and detailing all information on people, jobs, companies, events and workshops one has attended. This serves as a personal reference and makes it easier to go back and reanalyze decisions and opinions.

\section{Conclusions}

Exploring career options will come with surprises. With luck, it should not only expose strengths and weaknesses but also create enthusiasm and passion for specific topics. One absolutely essential ingredient in translating one's training in academia to a faculty job or industry is strong communication skills, as well as the courage to approach people across networks, asking for introductions or even cold calling others, especially those with professional paths that look interesting. Beyond academic services, we recommend exploring career development programs and innovation hubs around the world that host a range of networking and career opportunities. Attending a seminar or lecture series outside your normal scientific area is a good starting point for networking and communicating with others. For those with an academic career interests, these activities should increase your passion for pure science and knowledge for knowledge's sake while providing insights into how to build a successful career in academia by finding mentors. For those still exploring their future, these experiences should help increase one's awareness of the wide range of careers in the healthcare industry and lead to an early preparation toward a professional goal. It is critical to take a proactive approach to career building, adding new skill sets and identifying opportunities to broaden experiences. Finally, be curious and ready to challenge your own expectations, as they do not always match reality, and then take a chance and walk through opportunity's door to the career of your dreams.

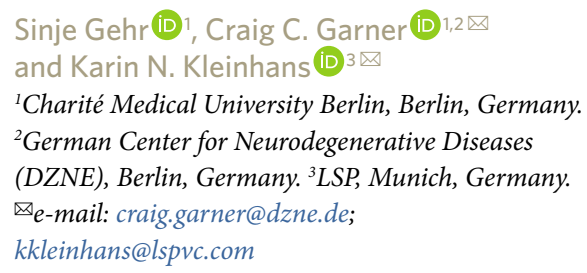

Published online: 9 June 2020

https://doi.org/10.1038/s41587-020-0552-x 
References

1. Hodgson, J. Nat. Biotechnol. 37, 502-512 (2019).

2. Senior, M. Nat. Biotechnol. 38, 408-415 (2020).

3. HBM Partners. HBM Pharma/Biotech M $\triangleleft A$ Report 2020 https://hbmpartners.com/media/docs/industry-reports/ HBM-Pharma-Biotech-M-A-Report-2020.pdf (February 2020)

4. Morrison, C. Nat. Biotechnol. 38, 126-131 (2020).

5. Price, E. The hunt for qualified biotech talent continues. PCI Synthesis https://www.pcisynthesis.com/ the-hunt-for-qualified-biotech-talent-continues/ (17 June 2019).

6. Toft, R. Biotech's looming talent crisis: 5 ways to prepare for the storm. Xconomy https://xconomy.com/san-diego/2018/06/05/ biotechs-looming-talent-crisis-5-ways-to-prepare-for-the-storm/ (5 June 2018).
7. Beninson, L. \& Daniels, R. The Next Generation of Biomedical and Behavioral Sciences Researchers: Breaking Through

(National Academies Press Washington, DC, 2018).

8. Graham, M. K., Park, B. H. \& Wyhs, N. Nat. Biotechnol. 36, 900-902 (2018).

9. Branan, J., Li, X. \& Wheeler, R. Nat. Biotechnol. 36, 1217-1219 (2018)

10. Stanford University. BioSci Careers. http://med.stanford.edu/ bioscicareers.html.

11. Tsai, J. W., Vanderford, N. L. \& Muindi, F. Nat. Biotechnol. 36, 552-553 (2018)

12. Charité Medical School Berlin. Career Development Initiative. https://www.ecn-berlin.de/career/CDI.html.

13. IDEO.org. The Field Guide to Human-Centered Design (IDEO.org/ Design Kit, 2015)
14. Rath, T. StrengthsFinder 2.0 (Gallup Press, 2007). 15. Freedman, T. Career Opportunities in Biotechnology and Drug Development (Cold Spring Harbor Laboratory Press, 2008).

16. KPMG. Unlocking the life sciences potential: key drivers to fully harvest the life sciences sector potential in the Netherlands. https://assets.kpmg/content/dam/kpmg/nl/pdf/2019/sector/ unlocking-the-life-sciences-potential.pdf (October 2019).

Competing interests

The authors declare no competing interests.

Additional information

Supplementary information is available for this paper at https://doi.org/10.1038/s41587-020-0552-x. 